\title{
On the Separation Mechanism between a Shark's Tooth and Its Jaw Base, with Special Emphasis on an Observation Made from a White Shark, Carcharodon carcharias
}

\author{
Erich K. Ritter ${ }^{1,2}$, Andreas Dellios ${ }^{3}$ \\ ${ }^{1}$ Department of Mathematics \& Statistics, University of West Florida, Pensacola, FL, USA \\ ${ }^{2}$ Shark Research Institute Global Shark Attack File, Princeton, NJ, USA \\ ${ }^{3}$ Shark School 5970 Osprey Place, Pensacola, FL, USA \\ Email: eritter@uwf.edu
}

How to cite this paper: Ritter, E.K. and Dellios, A. (2018) On the Separation Mechanism between a Shark's Tooth and Its Jaw Base, with Special Emphasis on an Observation Made from a White Shark, Carcharodon carcharias. Open Journal of Animal Sciences, 8, 329-334.

https://doi.org/10.4236/ojas.2018.83024

Received: June 19, 2018

Accepted: July 20, 2018

Published: July 23, 2018

Copyright $\odot 2018$ by authors and Scientific Research Publishing Inc. This work is licensed under the Creative Commons Attribution International License (CC BY 4.0).

http://creativecommons.org/licenses/by/4.0/

\begin{abstract}
Feeding is the likely cause for tooth shedding in sharks. Although the overall process of loosing teeth has been well studied, hardly any emphasis has been given to the actual separation mechanism between a shark's tooth base and the surrounding jaw tissue. Attention is given to this very process, in connection to a never before videotaped tooth loss of a white shark, Carcharodon carcharias, that occurred within 0.3 seconds. Since the shark did not bite into anything prior to this observation, the cause for this tooth loss does not seem feeding but fatigue related, triggered through a combination of mechanical and potentially biochemical degradation processes.
\end{abstract}

\section{Keywords}

Shark, Tooth Loss, Tooth Shedding, White Shark

\section{Introduction}

Teeth shedding among sharks is well studied, not just among extant but fossil species as well [1], thus reflects a rather long history [2] [3]. It is generally accepted that teeth shedding in sharks is largely caused due to feeding, and less so from fatigue [4]. Although the overall shedding process has been studied from different angles, the actual separation mechanism between a tooth's root and its connecting jaw tissue has largely been ignored [5].

The observation from a white shark, Carcharodon carcharias, loosing a tooth 
in an never before observed fashion is used to summarize the current knowledge of the actual process facilitating the disconnection between a shark's tooth and the surrounding jaw base, and tries to fit in this very process with the current understanding of tooth shedding in sharks.

\section{Case Report}

The video sequence of a $4 \mathrm{~m}$ male white shark, called "Herman", shedding its first lower anterior tooth, was recorded with a GoPro 4 off Guadalupe Island, Mexico, with a 1080i resolution and 120 frames per second (Figure 1). Herman's age was estimated to be between 28 and 32 years, with a 95\% confidence interval [6]. Individual frames were extracted through Final Cut Pro ${ }^{\circledR} \mathrm{X}$ by Apple ${ }^{\circledR}$. At the time of shedding, the shark had not bitten into anything prior to the recording nor was it in process of doing so that could have loosened or affected the tooth in question in any way. The tooth is further referred to as "al" after Shimada (2002) [7] [8] and Applegate and Espinosa-Arrubarrena (1996) [9].

\section{Discussion}

To understand tooth shedding in neoselachian sharks, tooth development, function and use, are essential to comprehend the process in question [5]. Probably, the most unique tooth feature among sharks, compared to any other group of vertebrates, is the conveyor-belt like polyphyodonty, the ongoing process of tooth development in lingual to labial direction over lower and upper jaw cartilages which has also been labelled a "many-for-one system" [5]. It has been suggested that on average a tooth is shed and replaced within one to four weeks [10] [11] [12], depending on its use and the shark's age and metabolism throughout a given season and water temperature [2] [13] [14]. It has further been indicated that lower teeth may be replaced quicker than upper ones [13] but that needs further examination on a species-to-species base. As such, a different replacement rate between upper and lower teeth is unknown for white sharks but the different crown angles of the functional teeth along the two jaw margins could affect the overall replacement rate between the two sets [15].

Due to the unique replacement system, shark teeth are not embedded in an alveolar manner as seen e.g., in mammals [16] [17] [18] but solely connected through collagenous and fibrous tissue, summarily labelled as dental ligament to the dermis of the dental lamina, not the jaw cartilage itself [19]. It is the most superficial layer of the dental ligament, composed of irregular collagen fiber

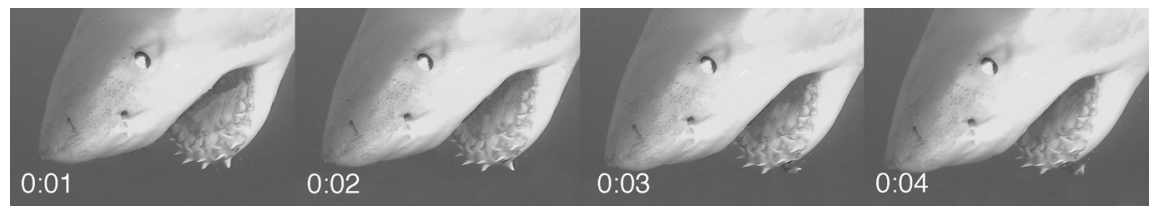

Figure 1. Tooth loss on a white shark. Numbers on individual frames represent the fraction of a second. 
bundles, called "Sharpey's fibers" [4] [19] [20], that attach to the tooth's base, the actual root of the tooth, and lateral surfaces next to it. Beside this superficial layer, there is also a deeper one that entails elastic fibers forming a flexible zone on top of the actual jaw cartilage. It is due to that zone that a tooth can move in a lingo-labial direction [21].

\section{Ways to Loose a Shark Tooth}

The loss of a tooth can happen in two ways, rather abrupt while e.g., biting into objects or then slow, taking up to several minutes (pers. obs.), should no force be projected onto a tooth. The latter reflects a gradual separation from the jaw's collagenous issue. It is often quite visible how the tooth loosely swings while still partially attached until the disconnection is complete. While breaking off a tooth seems largely a mechanical process due to the forces applied either caused by the structure the shark bites into, or then from pressure of succeeding teeth, especially when overlapping, is the disconnection more gradual, tissue breakdown is most likely [22], a biochemical tissue degradation could support the separation mechanism.

However, no explanations have ever been given on such tissue degradation among sharks that may occur between a tooth and its surrounding tissue. As a consequence, literature is not available how the actual separation between a tooth and its surrounding jaw tissue beside that breakage occurs [4] [23].

It is generally accepted that connective tissue binds the tooth base, its root, to the underlying tissue over the cartilage during the eruption phase of the tooth [5] [22] but the teeth still remain quite movable made possible due to a "band of fibres" [24]. Whenever a shark opens its mouth, especially during upper jaw eversion, its teeth are moved forward, enabled through an active motion of this connective tissue base [21] [25] [26]. Whenever an upper jaw is retracted, its teeth are also "pulled back" into a rather thick sheet of connective tissue, the dental ligament, consisting of three distinctive layers of varying thickness where the most basic one reflects the above mentioned elastic fibers that enable this teeth motion in the lingo-labial direction [21]. It is along those connective tissues that a separation must occur should a tooth not being broken out through biting into something.

Figure 1 shows the entire disconnection of an al within 0.3 seconds. White sharks belong to those species where more than one row of lower teeth is active, with prominent differences in insertion angles, the angle between axis of a tooth and main axis of the jaw [27].

The tooth in question was not involved in a preceding bite, nor could potential forces from overlapping teeth be an issue, leaving fatigue to be the most likely option. This is despite the argument that tooth replacement may stay ahead of such tooth failure [4]. Although the lower teeth of white sharks are rather slim, wear can still broaden the tip and edges, thus reducing its functionality. However, in order to hold prey, and in position for further handling, the lower anterior 
ones, a1, a2, and i1, the lower intermediate tooth, are protruding in different angles and not just in a perpendicular manner to the jaw axis as seen for most species. Thus, the outward angle of a1 likely still reflects an active tooth.

Since no external, mechanical force seem to have affected a1, but still a disconnection time of less than 0.3 seconds occurred, suggests not just tissue degradation as a likely cause but in addition to an as of yet unknown maintenance mechanism that may have facilitated the swiftness of this tooth loss. Shearing forces created between the water's flow based on the shark's forward motion and the tooth's angle towards it could be such a possibility where the water could have pushed onto the tooth's back surface. Additionally, the forward movement of the posterior tooth in the i file, could also facilitate the separation of a1, in connection to a flexibility loss of the fibers at its root. Both factors could speed up the tooth replacement rate of the lower jaw, what could then indeed indicate different replacement rates between upper and lower jaws in white sharks, as questioned above.

There is also the possibility that the connective tissue, underlying the conveyor-belt like process, starts to stretch over the jaw in a manner that the actual connective tissue bed surrounding the tooth in question starts to get deformed. Such could happen due to a mechanism described by Ramsay and Wilga (2007) [21] where the tension in a connective tissue sheet below the lower jaw is transferred onto the dental ligament. This could loosen its tightness that holds the tooth in place which as well could go hand in hand with a flexibility loss of the surrounding fibers. It has been mentioned in the past [25] [26] that lower teeth can also get erected which is ultimately connected to the teeth's underlying connective tissue. Such a procedure could then increase the above mentioned effect of tissue deformation.

The immediate discoloration of the surrounding water was likely blood stemming from the disruption of the tooth's blood vessels. Such would then indicate that the tooth has not died off prior to discarding and was indeed still functional at the time of separation from the surrounding tissue.

\section{Conclusion}

The very quick and complete tooth loss of an al from a white shark's lower jaw within a fraction of a second may reflect a so far unknown form in tooth shedding among sharks. None of the commonly accepted mechanism facilitating tooth loss in sharks can individually explain this observation. This offers the possibility that the disconnection of al's root from its surrounding jaw tissue reflects a combination of several mechanisms, culminating in the swift shedding of this lower tooth.

\section{References}

[1] Maisey, J.M., Turner, S., Naylor, G.J.P. and Miller, R.F. (2014) Dental Pattering in the Earliest Sharks: Implications for Tooth Evolution. Journal of Morphology, 275, 586-596. 
[2] Botella, H., Valenzuela-Rios, J.I. and Martinez-Perez, C. (2009) Tooth Replacement Rates in Early Chondrichthyans: A Qualitative Approach. Lethaia, 42, 365-376. https://doi.org/10.1111/j.1502-3931.2009.00152.x

[3] Smith, M.M., Johanson, Z., Underwood, C. and Diekwisch, T.G.H. (2012) Pattern Formation in Development of Chondrichthyan Dentitions: A Review of an Evolutionary Model. Historical Biology, 25, 127-142.

https://doi.org/10.1080/08912963.2012.662228

[4] Whitenack, L.B., Simkins, D.C. and Motta, P.J. (2011) Biology Meets Engineering: The Structural Mechanics of Fossil and Extant Shark Teeth. Journal of Morphology, 272, 169-179. https://doi.org/10.1002/jmor.10903

[5] Tucker, A.S. and Fraser, J. (2014) Evolution and Developmental Diversity of Tooth Regeneration. Seminars in Cell \& Developmental Biology, 25/26, 71-80. https://doi.org/10.1016/j.semcdb.2013.12.013

[6] Natanson, L.J. and Skomal, G.B. (2015) Age and Growth of the White Shark, Carcharodon carcharias, in the Western North Atlantic Ocean. Marine and Freshwater Research, 66, 387-398. https://doi.org/10.1071/MF14127

[7] Shimada, K. (2002) Dental Homologies in Lamniform Sharks (Chondrichthyes: Elasmobranchii). Journal of Morphology, 251, 38-72.

https://doi.org/10.1002/jmor.1073

[8] Shimada, K. (2002) The Relationship between the Tooth Size and Total Body Length in the White Shark, Carcharodon carcharias (Lamniformes: Lamnidae). Journal of Fossil Research, 35, 28-33.

[9] Applegate, S.P. (1996) The Fossil History of Carcharodon and Its Possible Ancestor, Cretolamna: A Study in Tooth Identification. In: Klimley, A.P. and Ainley, D.G., Eds., Great White Sharks. The Biology of Carcharodon carcharias, Academic Press, San Diego, 19-36. https://doi.org/10.1016/B978-012415031-7/50005-7

[10] Overstrom, N.A. (1991) Estimated Tooth Replacement in Captive Sand Tiger Sharks (Carcharias taurus Rafinesque 1810). Copeia, 1991, 525-526. https://doi.org/10.2307/1446602

[11] Correia, J.P. (1999) Tooth Loss Rate from Two Captive Sandtiger Sharks (Carcharias taurus). Zoo Biology, 18, 313-317. https://doi.org/10.1002/(SICI)1098-2361(1999)18:4<313::AID-ZOO5>3.0.CO;2-D

[12] Motta, P.J. and Wilga, C.D. (2001) Advances in the Study of Feeding Behaviors, Mechanisms, and Mechanics of Sharks. Environmental Biology of Fishes, 60, 131-156. https://doi.org/10.1023/A:1007649900712

[13] Luer, C.A., Blum, P.C. and Gilbert, P.W. (1990) Rate of Tooth Replacement in the Nurse Shark, Ginglymostoma cirratum. Copeia, 1990, 182-191. https://doi.org/10.2307/1445834

[14] Wass, R. (1973) Size, Growth, and Reproduction of the Sandbar Shark, Carcharhinus milberti, in Hawaii. Pacific Science, 27, 305-318.

[15] Powlik, J.J. (1995) On the Geometry and Mechanics of Tooth Position in the White Shark, Carcharodon carcharias. Journal of Morphology, 226, 277-288. https://doi.org/10.1002/jmor.1052260304

[16] Evans, R.D. and Sanson, G.D. (2003) The Tooth of Perfection: Functional and Spatial Constraints on Mammalian Tooth Shape. Biological Journal of the Linnean Society, 78, 173-191. https://doi.org/10.1046/j.1095-8312.2003.00146.x

[17] Freeman, P.W. and Lemen, C.A. (2007) The Trade-Off between Tooth Strength and Tooth Penetration: Predicting Optimal Shape of Canine Teeth. Journal of Zoology, 273, 273-280. https://doi.org/10.1111/j.1469-7998.2007.00325.x 
[18] Sunita, P.H., Marshall, S.J., Ryder, M.I. and Marshall, G.W. (2007) The Tooth Attachment Mechanism Defined by Structural, Chemical Composition and Mechanical Properties of Collagen Fibers in the Periodontum. Biomaterials, 28, 5238-5245. https://doi.org/10.1016/j.biomaterials.2007.08.031

[19] Moss, M.L. (1970) Enamel and Bone in Shark Teeth: With a Note on Fibrous Enamel in Fishes. Acta Anatomy, 77, 161-187. https://doi.org/10.1159/000143540

[20] Reif, W.-E. (1982) Evolution of Dermal Skeleton and Dentition in Vertebrates: The Odontode Regulation Theory. Evolutionary Biology, 15, 287-368. https://doi.org/10.1007/978-1-4615-6968-8_7

[21] Ramsay, J.B. and Wilga, C.D. (2007) Morphology and Mechanics of the Teeth and Jaws of White-Spotted Bamboo Sharks (Chiloscyllium plagiosum). Journal of Morphology, 268, 664-682. https://doi.org/10.1002/jmor.10530

[22] Huysseune, A. and Sire, J.-Y. (1998) Evolution of Patterns and Processes in Teeth and Tooth-Related Tissues in Non-Mammalian Vertebrates. European Journal of Oral Sciences, 106, 437-481. https://doi.org/10.1111/j.1600-0722.1998.tb02211.x

[23] Corn, K.A., Farina, S.C., Brash, J. and Summer, A.P. (2016) Modelling Tooth-Prey Interactions in Sharks: The Importance of Dynamic Testing. Royal Society Open Science, 3, Article ID: 160141. https://doi.org/10.1098/rsos.160141

[24] Smith, M.M., Fraser, G.J. and Johanson, Z. (2016) Origin of Teeth in Jawed Vertebrates. Infocus, 42, 5-17.

[25] Frazzetta, T.H. and Prange, C.D. (1987) Movements of Cephalic Components during Feeding in Some Requiem Sharks (Carcharhiniformes: Carcharhinidae). Copeia, 1987, 979-993. https://doi.org/10.2307/1445562

[26] Frazzetta, T.H. (1994) Feeding Mechanisms in Sharks and Other Elasmobranchs. In: Bels, V.L., Chardon, M. and Vanderwalle, P., Eds., Biomechanics of Feeding in Vertebrates: Advances in Comparative and Environmental Physiology, Springer, New York, 31-57. https://doi.org/10.1007/978-3-642-57906-6_3

[27] Lucifera, L.O., Menni, R.C. and Escalante, A.H. (2001) Analysis of Dental Insertion Angles in the Sandtiger Shark, Carcharias taurus (Chondrichthyes: Lamniformes). Cybium, 25, 23-31. 